\title{
ASSESSING SECONDARY SCHOOL STUDENTS' STATISTICAL REASONING, ATTITUDES TOWARDS STATISTICS, AND STATISTICS ANXIETY
}

\author{
SITI SHAHIRAH SAIDI \\ Universiti Malaysia Sabah \\ shahirah1203@yahoo.com \\ NYET MOI SIEW \\ Universiti Malaysia Sabah \\ sopiah@ums.edu.my
}

\begin{abstract}
Assessment on statistical reasoning is an area of academic interest in statistics education research in tandem with attitudes and anxiety towards statistics, since many studies report students are likely to encounter problems with statistics due to these two non-cognitive factors. In this study, 320 Tenth Grade science stream students from Sabah, Malaysia were tested using the Statistical Reasoning Test Survey (SRTS), the Survey of Attitudes towards Statistics (SATS), and the Statistical Anxiety Scale (SAS), which assessed their statistical reasoning, attitude, and anxiety, respectively. Generally, the findings revealed the students held $i$ ) a quantitative level in statistical reasoning, ii) a positive attitude towards statistics, and iii) a moderate level of statistics anxiety. A positive relationship between attitudes towards statistics and statistical reasoning, and a negative relationship between statistics anxiety and statistical reasoning were also observed. The Value, Interest, and Interpretation Anxiety components were predictor variables for statistical reasoning.
\end{abstract}

Keywords: Statistics education research; Attitudes towards statistics; Secondary school; Statistics anxiety; Statistical reasoning

\section{INTRODUCTION}

Statistical reasoning, along with statistical literacy and statistical thinking are the focus of trending goals of learning outcomes in statistics education. Rather than impose traditional methods like memorizing definitions, rules, and procedures, developing students' statistical reasoning skills should become a priority for educators of statistics education (Ben-Zvi \& Garfield, 2004). Previous studies have examined students' statistical reasoning in different statistical topics such as descriptive statistics (Ismail et al., 2015; Ismail \& Chan, 2015; Turegun \& Deerer, 2011; Ulusoy \& Altay, 2017), inferential statistics (Jacob \& Doerr, 2014), and probability (Agus et al., 2015; Agus et al., 2016; Primi et al., 2018). The studies revealed students still performed poorly in statistical reasoning, despite achieving good grades in statistics courses (Garfield, 1998; Tempelaar, 2004).

Another area of interest among researchers in statistics education is the assessment of non-cognitive factors related to students' performances in statistics. This includes attitudes towards statistics and statistics anxiety. Many past studies showcased a relationship between post-secondary students' statistical achievements and these two non-cognitive factors (Chiesi \& Primi, 2015; Chiesi \& Primi, 2010a; Lester, 2016; Nasser, 2004; Naccache, 2012; Tremblay et al., 2000). As more attention has been given to students' difficulties in learning statistics, evidence from previous studies has shown that students' attitudes towards statistics and statistics anxiety might influence students' statistical reasoning (Agus et al., 2015; Agus et al., 2016; Tempelaar et al., 2007; Wilson, 2006). Developing positive attitudes towards statistics and reducing statistics anxiety among students are two goals in statistical teaching (Baloglu, 2004; Liau et al., 2015). Additionally, it has been noted that students have a positive relationship between statistical reasoning and attitudes towards statistics (Tempelaar, 2004; Olani et al., 2011; Chiesi \& Primi, 2010b) and a negative relationship between statistical reasoning and statistics anxiety (Primi et al., 2018). These findings indicate that students with positive attitudes would have 
better statistical reasoning, while students with higher statistics anxiety tend to perform lower than expectations in statistical reasoning and vice versa. The literature also revealed the components measuring attitudes towards statistics and statistics anxiety were predictor variables for statistical reasoning (Agus et al., 2015; Tempelaar et al., 2007).

A survey of the research showed that while assessments related to the field of statistical reasoning have been conducted widely, they are limited in scope within the Malaysian educational scene. Studies related to this field have only been carried out in Malaysia within this decade, and earlier studies revealed the level of Malaysian students' statistical reasoning was still poor and unsatisfactory (Foo et al., 2016; Ismail \& Chan, 2013; Chan \& Ismail, 2013; Zaidan et al., 2012). Research on Malaysian students' attitude and anxiety towards statistics are well documented. Studies related to these two noncognitive factors, however, were mainly conducted on students in higher institutions and yielded mixed results. These studies showed that students exhibited a positive attitude towards statistics (Mahmud, 2010; Mahmud \& Osman, 2010; Mohamad Judi et al., 2011; Salim \& Mohd Ayub, 2017; Saidi \& Siew, 2019a), while in one finding, students were neutral towards statistics (Rosli \& Maat, 2017). Studies on statistics anxiety reflected that Malaysian higher institution students regularly exhibit a moderate level of statistics anxiety (Maat et al., 2016; Rosli et al., 2017).

To the best of our knowledge, in Malaysia at least, the literature shows a gap in the research of assessing statistical reasoning while simultaneously assessing the role of non-cognitive factors: attitudes towards statistics and statistics anxiety among secondary school students. Even at the global level, research assessing statistical reasoning, attitudes towards statistics, and statistics anxiety simultaneously particularly among secondary school students, also seems to be lacking. Therefore, this study presents an opportunity to do an in-depth investigation on these three variables on a secondary school sample. Further studies need to be carried out to explore statistical reasoning, attitude, and anxiety, with a focus on secondary school students, due to the lack of empirical evidence from previous studies regarding this context from this particular population. Specific investigation on the relationship between attitudes and feelings of anxiety towards statistics with statistical reasoning is apparently lacking; this gives us new impetus for this area of study.

\section{LITERATURE REVIEW}

\subsection{STUDENTS' STATISTICAL REASONING}

Ben-Zvi and Garfield (2004) defined statistical reasoning as "the way people reason with statistical ideas and make sense of statistical information" (p. 7). Ben-Zvi and Garfield further explained that statistical reasoning may involve connecting one concept to another such as measures of central tendency and variability, and may involve combining ideas about data and chance, which leads to the making of interpretations based on the data sets, data and graphical representations, and statistical summaries of data. Jones et al. (2004) defined statistical reasoning as the cognitive ability engaged by the students to explain the statistical process, particularly: Describing Data, Organising Data, Representing Data, and Analysing and Interpreting Data. The constructs of statistical reasoning proposed by Jones et al. (2004) were also similar to the model proposed by Jones et al. (2000) and Mooney's (2002) model of the development of statistical thinking. The constructs in their cognitive models of statistical reasoning and statistical thinking coincided with Shaugnessy et al.'s (1996) data handling statistical processes: organising, describing, representing, and analysing data.

Describing Data is related to the explicit reading of raw data or data presented in tables, charts, or graphical representations (Jones et al., 2004). This construct consists of two sub-processes: 1) Showing awareness of display features and 2) Identifying units of data values. Organising Data is related to arranging, categorising, or consolidating data into a summary form (Jones et al., 2004), and this construct consists of three sub-processes: 1) Grouping or ordering data; 2) Summarising data in terms of measures of central tendency; and 3) Summarising data in terms of measures of spread. Representing Data is displaying data in a graphical form (Jones et al., 2004), and this construct has two sub-processes: 1) Completing or constructing a data display for a given data set and 2) Evaluating the effectiveness of data displays in representing data. Analysing and Interpreting Data is related to recognising patterns and trends in the data and making inferences and predictions from data (Jones et al., 2004), and this construct also contains two sub-processes: 1) Reading between the data and 2) Reading beyond the 
data. We used these four constructs and nine sub-processes as a guide in assessing students' statistical reasoning.

\subsection{STUDENTS' ATTITUDES TOWARDS STATISTICS}

Generally, attitude is expressed as a summation of emotions and feelings experienced over time in the context of learning a course (Zhang et al., 2012). In statistics education, attitude towards statistics is described as the intense feelings, which are relatively stable and result from the positive or negative experiences encountered while learning statistics over a period of time (Martins et al., 2011). Schau (2003) categorised students' attitudes towards statistics into six components: Cognitive Competence, Value, Difficulty, Affect, Effort, and Interest. Cognitive Competence refers to the attitudes about intellectual knowledge and skills when applied to statistics, while Value refers to the attitudes about the usefulness, relevance, and worth of statistics in personal and professional life. Difficulty refers to the attitudes towards the difficulty of statistics as a subject, while Affect refers to the student's feelings towards statistics, whether the feelings are positive or negative. Effort refers to the amount of effort students spend on learning statistics and Interest refers to the students' level of individual interest in statistics. Students with positive attitudes towards statistics should develop statistical thinking, use statistical knowledge to solve daily life problems, and have a desire to participate in more advanced statistical courses in the future. On the contrary, students with negative attitudes towards statistics may tend to display their anxiety towards statistics in the classroom (Mohamad Judi et al., 2011).

\subsection{STUDENTS' STATISTICS ANXIETY}

There are two types of anxiety experienced by a person: state anxiety and trait anxiety (Spielbeger, 1966). According to Tanaka et al. (2006), state anxiety refers to the unbalanced and temporary experiences of tension, fear, and intense emotion of the self-dependent neural system in a specific situation. Meanwhile, trait anxiety refers to a general tendency to react with anxiety to perceived threats in the environment (Harikawa \& Yagi, 2012). In statistics education, Onwuegbuzie et al. (1997) categorised statistics anxiety as a state anxiety. They defined statistics anxiety as a state anxiety reaction that happens when a student is confronted with statistics in any form, time, or situation. Statistics anxiety also occurs when students encounter statistics at any form and level, which involves a complex array of emotional reactions that can obstruct the learning process (Onwuegbuzie \& Daley, 1999). Meanwhile, Vigil-Colet et al. (2008) categorised statistics anxiety into three components: Examination Anxiety, Asking for Help Anxiety, and Interpretation Anxiety. Examination Anxiety refers to the anxiety that occurs when the students take a statistics exam, while Asking for Help Anxiety refers to feelings of anxiety when asking the teacher or other students about statistics. Interpretation Anxiety refers to the anxiety when students have to interpret statistical data and understand the formulae used in statistics. Previous studies revealed that students who held higher statistics anxiety levels in statistical learning tend to perform poorer in statistics (Bell, 2001; Hanna \& Dempster, 2009; Onwuegbuzie, 2003).

\section{PURPOSE OF THE STUDY}

This study aimed to assess statistical reasoning, attitude towards statistics, and statistics anxiety among secondary school students. The operational definition of statistical reasoning was derived from Jones' et al.'s (2004) constructs. They were Describing Data, Organising Data, Representing Data, and Analysing and Interpreting Data. The operational definition of attitude towards statistics was based on Schau's (2003) components, Cognitive Competence, Value, Difficulty, Affect, Effort, and Interest. Operalization of the term 'statistics anxiety' was derived from Vigil-Colet et al.'s (2008) components, Examination Anxiety, Asking for Help Anxiety, and Interpretation Anxiety. There were two research questions guiding this research:

1. What is the level of students' statistical reasoning, attitudes towards statistics, and statistics anxiety?

2. What is the extent of the relationship between attitudes towards statistics and statistics anxiety with overall statistical reasoning? 


\section{RESEARCH METHODOLOGY}

\subsection{INSTRUMENTATION}

Three research instruments were used in the study, the Statistical Reasoning Test Survey (SRTS), the Survey of Attitudes towards Statistics (SATS), and the Statistical Anxiety Scale (SAS) instrument. Since the teaching and learning lessons and materials were in Malay, these instruments were constructed in the Malay language, with validity evidence provided using a back-translation technique. Meanwhile, an English version was prepared as well because some students might have preferred to answer the instruments in English. Following the common practice in Malaysian Mathematics secondary school assessment, the items in the instruments were arranged in such a way that the English item was placed below the Malay item. Additionally, a pilot test was employed to test the validity and reliability of the instruments.

Statistical Reasoning Test Survey. The SRTS instrument used to assess statistical reasoning in this study was adapted from Saidi and Siew (2019b). The original instrument consisted of only12 items, but this study added two more items: 1 item in the Organising Data and 1 item in the Representing Data construct. The SRTS instrument was a combination of a subjective test and an open-ended questionnaire, which consisted of 14 items. The score for each of the individual items and constructs in the SRTS instrument ranged from 1 to 4: 1 - Idiosyncratic (Level 1), 2 -Transitional (Level 2), 3 Quantitative (Level 3), and 4 -Analytical (Level 4). The SRTS instrument comprised four constructs: Describing Data, Organising Data, Representing Data, and Analysing and Interpreting Data as proposed by Jones et al. (2004). Describing Data consisted of two items which assessed two subprocesses: 1) Showing awareness of display features (1 item): "Examine the graphs carefully. What information do you get from the graphs?" and 2) Identifying units of data values (1 item): "Based on the table above, what is the highest value of marks for both of the subjects? Please explain how to get the answer". Organising Data consisted of seven items which assessed three sub-processes: 1) Grouping or ordering data (1 item): "Based on the data above, organise the data into the table below. Can you organise or classify the data in different ways? Explain what you will do."; 2) Summarising data in terms of measures of central tendency (3 items) - Example: "What is the mean for the marks of Mathematics subject? Explain how you determine the mean." and 3) Summarising data in terms of measures of spread (3 items) - Example: "What is the mark for the Science subject? Explain how you determine the range." Representing Data consisted of two items, which assessed two sub-processes: 1) Completing or constructing a data display for a given data set (2 items) - Example: "Based on the table in 1a, construct a histogram and an ogive graph in the graph paper provided at the next page." and 2) Evaluating the effectiveness of data displays in representing data (1 item): "In your opinion, which graph do you think represents the data better, histogram or ogive? Explain why by stating the advantages." Analysing and Interpreting Data consisted of two items, which assessed two subprocesses: 1) Reading between the data (1 item): "Compare the distribution of the two graphs with respect to shape, measures of center, and spread. Explain your answer(s)." and 2) Reading beyond the data (1 item): "In your opinion, which type of average (mean, median, and mode) is the most suitable to be used to compare the students' achievement for both subjects? Explain why." In this study, evidence for validity of the SRTS instrument was provided from the analysis of the misfit order of the items in a Rasch model. According to Boone et al. (2014) and Bond and Fox (2015), there are three criteria that can be used to assess the item fit: 1. Outfit Mean Square Values (MNSQ) - value must be between 0.50 and $1.50 ; 2$. Outfit Z-Standardized Values (ZSTD) - value must be between -2.00 and 2.00; and 3. Point Measure Correlation (PTMEA-CORR) - value must be between 0.40 and 0.85 . The assessment on the item fit in the Rasch analysis revealed that all of the items in the SRTS instrument fulfilled all the criteria for Outfit MNSQ, Outfit ZSTD, and PT-MEASURE CORR, indicating that the items in the instrument were suitable to be used on the sample of the study. Additionally, the reliability of the SRTS instrument, which was also analysed through the Rasch analysis, reported favorable indices for Cronbach's alpha (0.91), item reliability (0.97), and person reliability (0.90). In addition, two mathematics teachers also were employed to assess the inter-rater reliability of the SRTS instrument. 
The results from Cohen's Kappa revealed that all of the items in the SRST instrument had at least strong inter-rater reliability index (ranged from $0.825-1.000$ ).

Survey of Attitudes towards Statistics. The instrument that measured attitudes towards statistics was based on the adaptation done by Saidi and Siew (2019c) of the original Survey of Attitudes towards Statistics (Schau et al., 1995; Schau, 2003). It was a seven-point Likert-type scale questionnaire with 30 items. The responses ranged from 1 (strongly disagree) through 4 (no opinion) to 7 (strongly agree). Higher scores correspond to a more positive attitude. It consisted of six components: 1) Cognitive Competence (6 items) - Example: "I can learn statistics"; 2) Value (7 items) - Example: "Statistics is relevant in my life."; 3) Difficulty (4 items) - Example: "Statistics is an easy subject."; 4) Affect (5 items) - Example: "I will like statistics."; 5) Effort (4 items) - Example: "I plan to complete all of my statistics home work."; and 6) Interest (4 items) - Example: "I am interested in using statistics.". Some items in the SATS were modified slightly for the secondary school students' understanding. Several words or terms in the original items were unsuitable for the sample of the study due to differences in the learning context between secondary school and higher institution students. For example, the original item "I will enjoy taking statistics courses" under the Affect component was modified to "I will enjoy learning statistical topics" because statistics is not offered as a single course, but is included as a topic in the Malaysian Mathematics textbook. Besides that, the word "assignment" in the original item "I plan to complete all of my statistics assignment" under the Effort component was changed to "homework" because the students in the study were more familiar with this word. Additionally, the original items that used the word "equation" were changed to "formula" because this term is used in Malaysian Mathematics textbooks. The results of the Confirmatory Factor Analysis (CFA) affirmed the relevance of the six-factor model of SATS with its 30 items. Cronbach's alpha revealed that the components in SATS had at least good internal consistency reliability (Cognitive Competence $=0.889$; Value $=0.893 ;$ Difficulty $=0.868 ;$ Affect $=0.859 ;$ Effort $=0.898 ;$ Interest $=0.914 ;$ Overall $=0.958)$.

Statistical Anxiety Scale. The instrument that measured statistics anxiety was adapted from the Statistical Anxiety Scale instrument introduced by Vigil-Colet et al. (2008). It was a five-point Likerttype scale questionnaire ranging from 1 (not anxious) to 5 (very anxious), where higher scores correspond to a higher anxiety. It consisted of 18 items and three components which were: 1) Examination Anxiety (4 items) - Example: "Studying for an examination, particularly in statistics topic." 2) Asking for Help Anxiety (8 items) - Example: "Asking the teacher on how to do an exercise"; and 3) Interpretation Anxiety (6 items) - Example: "Interpreting the meaning of a table in an article.". Several items in this SAS instrument were also modified slightly, for instance, the original item "Studying for an examination in a statistics course" under the Examination Anxiety component was changed to "Studying for an examination, particularly in a statistics topic." Meanwhile, the original item, "Asking the teacher how to use a probability table" under the Asking for Help Anxiety component was changed to "Asking the teacher how to construct a frequency table", because the students would not encounter and learn probability-related topics until the next grade. The analysis via CFA provided validity evidence for the three-factor model of the SAS instrument (18 items). The Cronbach's alpha value revealed that the components in the SAS conveyed at least a good internal consistency reliability (Examination Anxiety $=0.814$; Asking for Help Anxiety $=0.913$; Interpretation Anxiety $=0.838$; Overall $=0.920$ ).

\subsection{RESEARCH PROCEDURE}

Participants. This study employed a cross-sectional survey research design and was executed in the Northern West Coast of Sabah, Malaysia. This location contains four districts and 32 secondary schools, but only 30 secondary schools offer a science stream education to students. The sample consisted of 320 Tenth Grade science stream students, aged 16 years, with 121 males (37.8\%) and 199 females $(62.2 \%)$. In this study, as the research location consisted of four different districts, we stratified the research location first based on the four districts using stratified sampling. Then, since all of the schools in each of the district have different number of students, the selection of the schools within each stratum was done by using the probability proportional to size (PPS) technique sampling. In Malaysian schooling system, students who have completed the lower secondary education can choose between 
two main streams (Arts or Science streams) upon entering the upper secondary education. Students who take on science stream education have more exposure to statistics-related contents.

The Malaysian KBSM (Kurikulum Bersepadu Sekolah Menengah) secondary curriculum was in place prior to the latest KSSM curriculum (Kurikulum Standard Sekolah Menengah), which was introduced circa 2017. Note that Malaysian Seventh graders in 2017 were the first students to experience the latest KSSM curriculum, while the students in the study who were Tenth Graders in 2019 were still following the previous curriculum, which was the KBSM curriculum. In the Mathematics KBSM curriculum, teaching and assessment of statistical learning in the Malaysian secondary school system relied on traditional approaches, which focused on computation and procedural knowledge, such as computing statistical measures and constructing statistical graphs. Arguably, most of the existing statistical problems in the KBSM Malaysian Mathematics textbooks were old-fashioned techniques, routine, and close-ended problems, while the elements of statistical reasoning still remained largely underexposed (Chan et al., 2015a; 2015b). The elements of statistical reasoning such as making interpretations, comparisons, inferences, reasoning, and thinking were not given much attention in statistical teaching. Therefore, the involvement of Tenth Grade science stream students studying under the KBSM curriculum in this study could determine the extent to which this curriculum could produce students who could reason statistically, in line with the goals of learning outcomes in statistics education.

Procedure. In the Malaysian schooling system, students in each grade start the school session at the beginning of the year and end at the end of the year. During this learning period, Tenth Grade science stream students will only study statistical topics in the Mathematics and Additional Mathematics curriculum in the second half of the year, as these statistical topics are placed at the end of the syllabus in the textbooks. Due to this, the data collection was carried out in the second half of the year 2019 (from June to October), and it involved 30 science stream classes. We also assumed that some students from different schools might have already learned the statistical topics while some had not, thus we set the time to collect the data based on whether the students had already learned the statistical topics. The instruments were administered to the students during mathematics classes with the help of teachers in the involved schools. Students were also informed about the purpose of the study prior to distribution of instruments and given assurance of confidentiality. There were no incentives given to the students and the students were informed that anyone could withdraw from the research without penalty. Each student received one questionnaire comprised of the SRTS, SATS and SAS instruments, starting with SRTS, followed by the SATS and SAS instruments. Students were advised to spend 60 minutes answering the SRTS instrument, and 10 minutes to answer both SATS and SAS instruments. The prescribed time to answer the questionnaire was 70 minutes and all students completed the questionnaire in this time limit.

\subsection{DATA ANALYSIS}

Before analysing the relationship between overall statistical reasoning and both attitudes towards statistics and statistics anxiety, the individual levels for statistical reasoning, attitude towards statistics, and statistics anxiety were analysed to gain a better idea of how the students performed in these three scales. Mooney's (2002) method was adapted using the mean score to determine the level of students' statistical reasoning within each of the four constructs and overall. Based on the framework developed by Saidi and Siew (2019b), the level of reasoning was determined for all items in the four constructs, and then the mean score related to the constructs was calculated in order to determine the level of students' statistical reasoning towards the constructs. According to Mooney (2002), a mean score with a value halfway between the two levels is to be rounded down to the lower level. A student who had a mean score of 1.0 to 1.5 was classified at the Idiosyncratic level (Level 1) in statistical reasoning, while a student who received a mean score higher than 1.5 and less than or equal to 2.5 was considered as having a Transitional level (Level 2) of statistical reasoning and so forth. The overall statistical reasoning was assessed by computing the mean score for all 14 items, and Mooney's (2002) method was applied to find the overall level of statistical reasoning held by the students. Students' levels of statistical reasoning were categorised into four levels: Idiosyncratic (1.00-1.50), Transitional (1.512.50), Quantitative (2.51-3.50), and Analytical (3.51-4.00). 
The level of students' attitudes towards statistics with respect to the individual components and overall score was determined using the mean score: computing the mean response to the items making up each component and the complete instrument. According to Ashaari et al. (2012), the level of students' attitudes towards statistics can be categorised into three levels: Negative (1.00 - 3.50), Neutral (3.51-4.49), and Positive (4.50-7.00). The same procedure was applied in determining the level of students' statistics anxiety with respect to its components and overall. Previous studies used the total score to determine the level of students' statistics anxiety. A higher score indicates a higher level of anxiety (Chew \& Dillon, 2015; Hedges, 2017; Maat et al., 2016; Rosli et al., 2017). However, this did not give a clear indicator to determine the level of anxiety for each of the statistics anxiety components and overall - whether the levels were high, moderate or low. This study showed the level of students' statistics anxiety was also determined by using the mean score. Students' statistics anxiety was categorised into three levels: Low (1.00-2.33), Moderate (2.34-3.66), and High (3.67-5.00).

A Pearson Product Moment Correlation Coefficient was used to determine the bivariate relationship between attitude towards statistics and statistics anxiety with statistical reasoning. Meanwhile, a multiple linear regression analysis was applied to describe the multivariable relationship between the selected predictor variables (the components of attitude and anxiety in statistics) with the response variable (overall statistical reasoning), as well as to find the important predictor variables for overall statistical reasoning. Prior to the analysis, the data were tested for the normality, linearity, and multicollinearity assumptions. The result from the Skewness and Kurtosis test showed no evidence of a departure from normality of the data since all of the results were in the range between -2.0 and +2.0 (Chua, 2009). The linearity assumption was checked through the residuals, and no relationship between the residuals and the predicted values (homoscedasticity) was revealed by the analysis, which implies linearity (Lay et al., 2016). The multicollinearity assumption was checked through the tolerance value and Variance Inflation Factor (VIF) value in regression analysis, and it was discovered that the tolerance value and VIF value for all of the predictor variables was over 0.1 and less than 10 , respectively, which indicated a lack of multicollinearity between the predicted variables (Hair et al., 2014).

\section{RESULTS}

\subsection{RESEARCH QUESTION 1}

The level for statistical reasoning overall and by construct is presented in Figure 1. The level with the highest percentage (55.0\%) for the overall statistical reasoning was the Quantitative level (Level 3) with mean score of 2.60 and standard deviation of 0.68. Meanwhile, in the context of the statistical reasoning constructs, the Quantitative level also had the highest percentage for the Describing Data $(63.4 \%$, Mean $=2.78, S D=0.81)$, Organising Data $(49.1 \%$, Mean $=2.76, S D=0.82)$, and Representing Data $(61.3 \%$, Mean $=2.77, S D=0.78)$ constructs. For the Analysing and Interpreting Data construct, the level with the highest percentage $(64.1 \%)$ was the Idiosyncratic level with mean score of 1.62 and standard deviation of 0.70 .

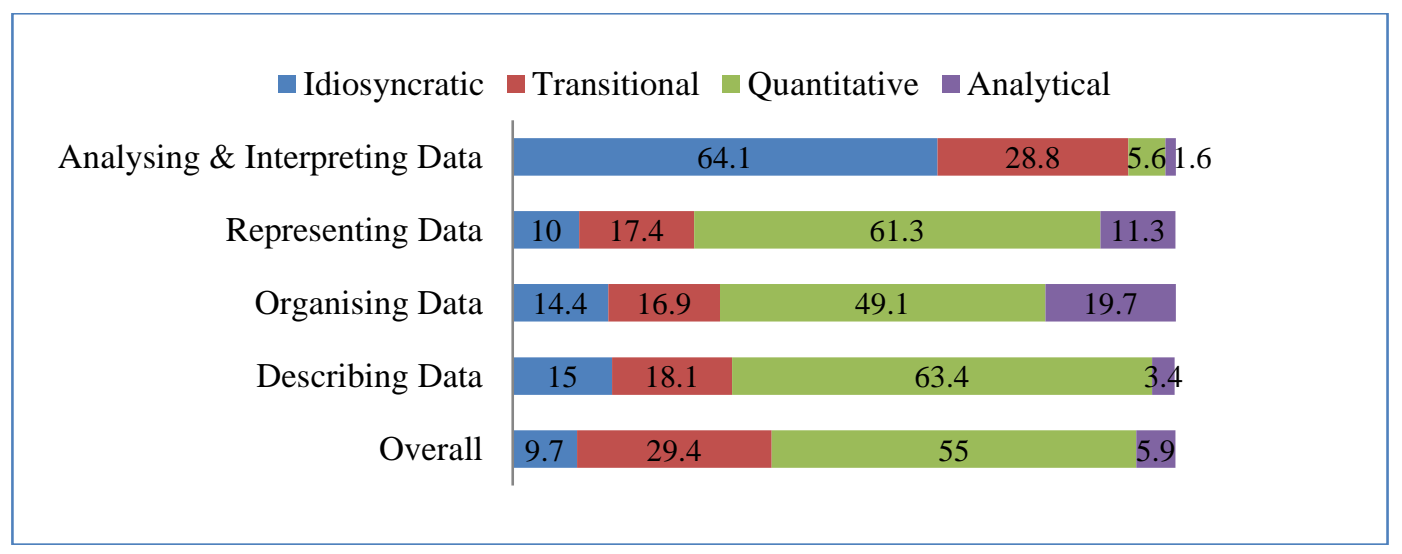

Figure 1. Percentage for the level of overall statistical reasoning and across the four constructs $(N=320)$ 
Figure 2 shows the level for the overall attitude towards statistics and its components held by the students. Based on this figure, a majority of students held an overall positive attitudes towards statistics (74.4\%) with mean score of 5.02 and standard deviation of 0.82 . Meanwhile, on the attitudes towards statistics components, a majority of the students also held positive attitudes towards statistics in all of the components, starting with Effort $(83.1 \%$, Mean $=5.58, S D=1.20)$, and followed by Cognitive Competence $(82.8 \%$, Mean $=5.25, S D=0.90)$, Interest $(73.1 \%$, Mean $=5.15, S D=1.33)$, Affect $(72.2 \%$, Mean $=5.10, S D=1.13)$, Difficulty $(61.3 \%$, Mean $=4.64, S D=1.12)$, and Value $(49.7 \%$, Mean $=4.56$, $\mathrm{SD}=1.01)$.

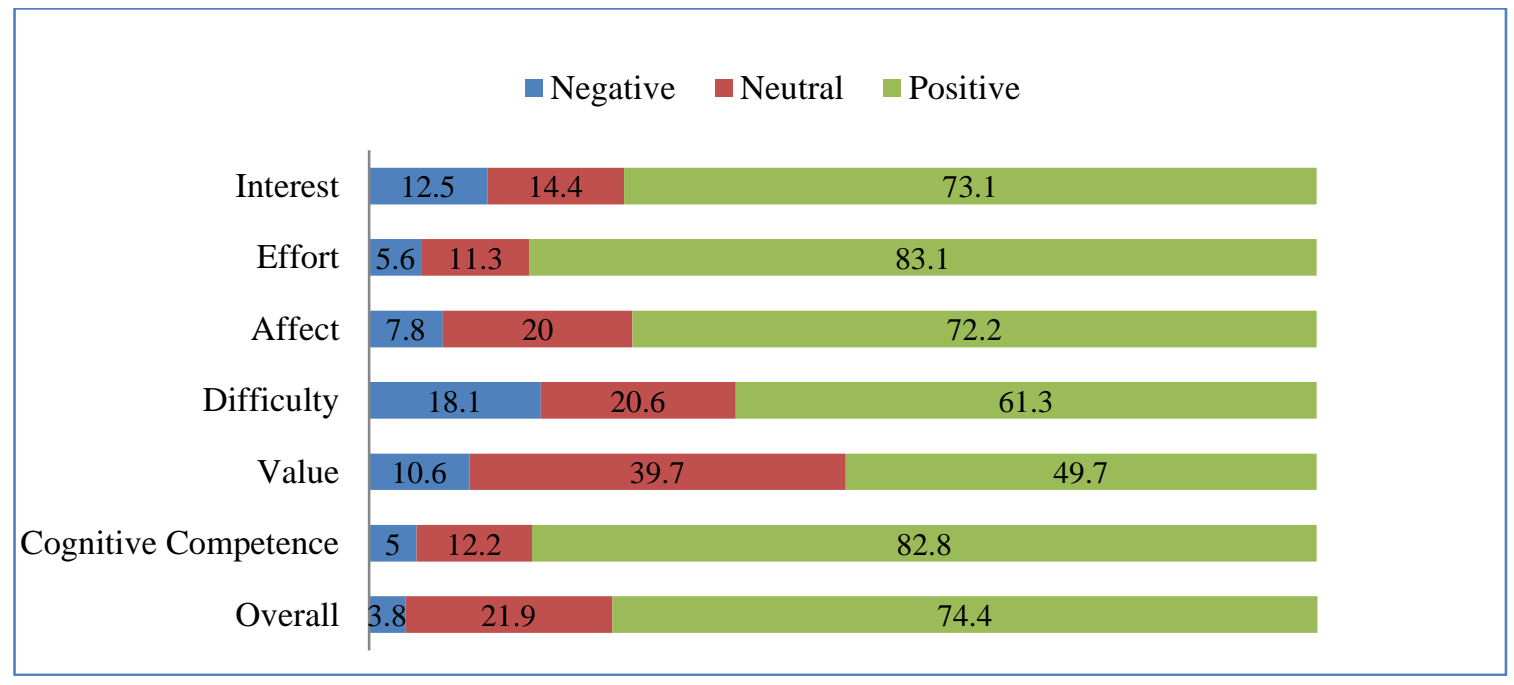

Figure 2. Percentage for the level of overall attitudes towards statistics and across the six components $(N=320)$

In Figure 3, it was discovered that $59.4 \%$ of students held a moderate level of statistics anxiety with a mean score of 2.70 and standard deviation of 0.66. Meanwhile, in the Examination Anxiety component, $49.7 \%$ of students also held a moderate level of statistics anxiety with a mean score of 3.14 and standard deviation of 0.83 . In Interpretation Anxiety component, $58.1 \%$ of students held a moderate level of anxiety as well with a mean score of 2.78 and standard deviation of 0.74 . Meanwhile in the Asking for Help Anxiety component, $49.1 \%$ of students held a low level of anxiety with a mean score of 2.42 and standard deviation of 0.88 .

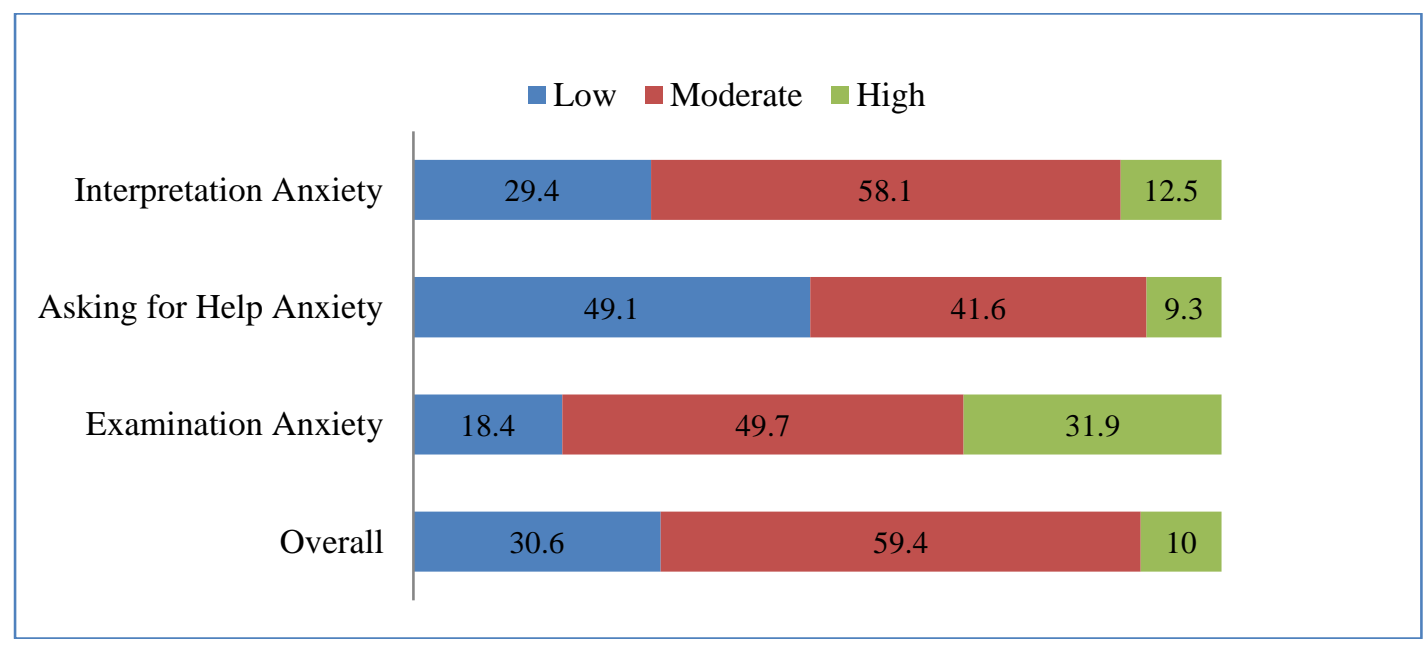

Figure 3. Percentage for the level of overall statistics anxiety and across the three components $(N=320)$ 


\subsection{RESEARCH QUESTION 2}

Table 1 shows the correlations between the overall score of statistical reasoning and the individual components and overall score of attitudes towards statistics and statistics anxiety. Based on Table 1, the Pearson Product Moment Correlation Coefficient analysis revealed that Value had the strongest positive bivariate correlation with overall statistical reasoning $(r=0.20, p<0.001)$, followed by overall attitudes towards statistics $(r=0.13, p=0.020)$ and Cognitive Competence $(r=0.13, p=0.026)$. The strength of all of the correlations was very weak. For the statistics anxiety component, the strongest bivariate correlation was between Interpretation Anxiety and overall statistical reasoning $(r=-0.23, p$ $<0.001)$. Overall statistics anxiety $(r=-0.18, p<0.001)$ and Asking for Help Anxiety $(r=-0.12, p=$ 0.026 ) also showed an association with overall statistical reasoning. Similar to the results of attitudes towards statistics, the strength of all of the correlations between statistics anxiety with overall statistical reasoning was very weak and somewhat negative. 
Table 1. Correlation matrix $(N=320)$

\begin{tabular}{|c|c|c|c|c|c|c|c|c|c|c|c|}
\hline & 1 & 2 & 3 & 4 & 5 & 6 & 7 & 8 & 9 & 10 & 11 \\
\hline 1. SR Overall & --- & & & & & & & & & & \\
\hline 2. SATS Overall & $\begin{array}{c}0.13 \\
(0.02)\end{array}$ & --- & & & & & & & & & \\
\hline $\begin{array}{l}\text { 3. Cognitive } \\
\text { Competence }\end{array}$ & $\begin{array}{c}0.13 \\
(0.03)\end{array}$ & $\begin{array}{c}0.77 \\
(0.00)\end{array}$ & --- & & & & & & & & \\
\hline 4. Value & $\begin{array}{c}0.20 \\
(0.00)\end{array}$ & $\begin{array}{c}0.70 \\
(0.00)\end{array}$ & $\begin{array}{c}0.44 \\
(0.00)\end{array}$ & --- & & & & & & & \\
\hline 5. Difficulty & $\begin{array}{c}0.08 \\
(0.16)\end{array}$ & $\begin{array}{c}0.71 \\
(0.00)\end{array}$ & $\begin{array}{c}0.57 \\
(0.00)\end{array}$ & $\begin{array}{c}0.27 \\
(0.00)\end{array}$ & --- & & & & & & \\
\hline 6. Affect & $\begin{array}{c}0.10 \\
(0.08)\end{array}$ & $\begin{array}{c}0.84 \\
(0.00)\end{array}$ & $\begin{array}{c}0.57 \\
(0.00)\end{array}$ & $\begin{array}{c}0.44 \\
(0.00)\end{array}$ & $\begin{array}{c}0.65 \\
(0.00)\end{array}$ & --- & & & & & \\
\hline 7. Effort & $\begin{array}{c}0.07 \\
(0.21)\end{array}$ & $\begin{array}{c}0.72 \\
(0.00)\end{array}$ & $\begin{array}{c}0.49 \\
(0.00)\end{array}$ & $\begin{array}{c}0.33 \\
(0.00)\end{array}$ & $\begin{array}{c}0.39 \\
(0.00)\end{array}$ & $\begin{array}{c}0.55 \\
(0.00)\end{array}$ & --- & & & & \\
\hline 8. Interest & $\begin{array}{l}-0.02 \\
(0.71)\end{array}$ & $\begin{array}{c}0.78 \\
(0.00)\end{array}$ & $\begin{array}{c}0.45 \\
(0.00)\end{array}$ & $\begin{array}{c}0.43 \\
(0.00)\end{array}$ & $\begin{array}{c}0.43 \\
(0.00)\end{array}$ & $\begin{array}{c}0.63 \\
(0.00)\end{array}$ & $\begin{array}{c}0.58 \\
(0.00)\end{array}$ & --- & & & \\
\hline 9. SAS Overall & $\begin{array}{l}-0.18 \\
(0.00)\end{array}$ & $\begin{array}{l}-0.27 \\
(0.00)\end{array}$ & $\begin{array}{l}-0.22 \\
(0.00)\end{array}$ & $\begin{array}{l}-0.20 \\
(0.00)\end{array}$ & $\begin{array}{l}-0.18 \\
(0.00)\end{array}$ & $\begin{array}{l}-0.26 \\
(0.00)\end{array}$ & $\begin{array}{l}-0.15 \\
(0.01)\end{array}$ & $\begin{array}{l}-0.20 \\
(0.00)\end{array}$ & --- & & \\
\hline $\begin{array}{l}\text { 10. Examination } \\
\text { Anxiety }\end{array}$ & $\begin{array}{l}-0.05 \\
(0.38)\end{array}$ & $\begin{array}{l}-0.20 \\
(0.00)\end{array}$ & $\begin{array}{l}-0.15 \\
(0.01)\end{array}$ & $\begin{array}{l}-0.11 \\
(0.05)\end{array}$ & $\begin{array}{l}-0.18 \\
(0.00)\end{array}$ & $\begin{array}{l}-0.31 \\
(0.00)\end{array}$ & $\begin{array}{l}-0.04 \\
(0.51)\end{array}$ & $\begin{array}{l}-0.13 \\
(0.02)\end{array}$ & $\begin{array}{c}0.64 \\
(0.00)\end{array}$ & --- & \\
\hline $\begin{array}{l}\text { 11. Asking for } \\
\text { Help Anxiety }\end{array}$ & $\begin{array}{l}-0.12 \\
(0.03)\end{array}$ & $\begin{array}{l}-0.25 \\
(0.00)\end{array}$ & $\begin{array}{l}-0.18 \\
(0.00)\end{array}$ & $\begin{array}{l}-0.16 \\
(0.01)\end{array}$ & $\begin{array}{l}-0.14 \\
(0.01)\end{array}$ & $\begin{array}{l}-0.19 \\
(0.00)\end{array}$ & $\begin{array}{l}-0.19 \\
(0.00)\end{array}$ & $\begin{array}{l}-0.25 \\
(0.00)\end{array}$ & $\begin{array}{c}0.87 \\
(0.00)\end{array}$ & $\begin{array}{c}0.31 \\
(0.00)\end{array}$ & --- \\
\hline $\begin{array}{l}\text { 12. Interpretation } \\
\text { Anxiety }\end{array}$ & $\begin{array}{l}-0.23 \\
(0.00)\end{array}$ & $\begin{array}{l}-0.18 \\
(0.00)\end{array}$ & $\begin{array}{l}-0.19 \\
(0.00)\end{array}$ & $\begin{array}{l}-0.21 \\
(0.00)\end{array}$ & $\begin{array}{l}-0.11 \\
(0.01)\end{array}$ & $\begin{array}{l}-0.16 \\
(0.00)\end{array}$ & $\begin{array}{l}-0.06 \\
(0.27)\end{array}$ & $\begin{array}{l}-0.05 \\
(0.39)\end{array}$ & $\begin{array}{c}0.81 \\
(0.00)\end{array}$ & $\begin{array}{c}0.47 \\
(0.00)\end{array}$ & $\begin{array}{c}0.52 \\
(0.00)\end{array}$ \\
\hline
\end{tabular}

$p$-values in parentheses 
The multiple linear regression analysis (Table 2) tested a model in which the SATS and SAS components served as predictor variables for overall statistical reasoning. The model explained about $10.3 \%\left(R^{2}=0.103\right)$ of the variability of overall statistical reasoning, with the Interest $(\beta=-0.104$, Beta $=-0.204, p=0.009)$, Interpretation Anxiety $(\beta=-0.184$, Beta $=-0.201, p=0.004)$, and Value $(\beta=$ 0.121 , Beta $=0.180, p=0.006$ ) components being the important predictors of overall statistical reasoning.

Table 2. Multiple linear regression analysis $(N=320)$

\begin{tabular}{lccccc}
\hline & \multicolumn{2}{c}{$\begin{array}{c}\text { Unstandardised } \\
\text { Coefficients }\end{array}$} & $\begin{array}{c}\text { Standardised } \\
\text { Coefficients }\end{array}$ & & \\
\cline { 2 - 3 } & $\beta$ & Std. Error & Beta & $t$ & $p$-value \\
\cline { 2 - 3 } (Constant) & 2.406 & 0.331 & & 7.263 & 0.000 \\
Cognitive Competence & 0.019 & 0.056 & 0.025 & 0.334 & 0.738 \\
Value & 0.121 & 0.043 & 0.180 & 2.785 & 0.006 \\
Difficulty & 0.013 & 0.045 & 0.022 & 0.297 & 0.767 \\
Affect & 0.047 & 0.055 & 0.078 & 0.859 & 0.391 \\
Effort & 0.027 & 0.040 & 0.048 & 0.664 & 0.507 \\
Interest & -0.104 & 0.040 & -0.204 & -2.636 & 0.009 \\
Examination Anxiety & 0.068 & 0.052 & 0.083 & 1.292 & 0.197 \\
Asking for Help Anxiety & -0.029 & 0.051 & -0.037 & -0.567 & 0.571 \\
Interpretation Anxiety & -0.184 & 0.064 & -0.201 & -2.873 & 0.004 \\
\hline
\end{tabular}

\section{DISCUSSION}

\subsection{STUDENTS' PERFORMANCE ON THE INVIDUAL SCALES}

This study demonstrated students could achieve Level 3 (Quantitative level) in statistical reasoning, indicating they could understand several aspects of the statistical processes in the tasks, but lack the ability to fully integrate them. It was also reasoned that their ability revolved around enumerating, describing, classifying, and executing procedures. With respect to the statistical reasoning constructs, most of the students held a Quantitative level in the Describing Data, Organising Data, and Representing Data constructs. This result was expected since the statistical topics under the Malaysian Mathematics KBSM curriculum put emphasis on the aspects of computation of statistical measures and constructing graphs. These topics are assessed in upper secondary Mathematics and Additional Mathematics KBSM tests and examinations. In addition, Malaysian Mathematics and Additional Mathematics KBSM textbooks contain questions and contents that focus heavily on calculation and procedural skills. Due to this, students might easily master and understand these concepts, which contributes to the high level of reasoning in the Describing Data, Organising Data, and Representing Data constructs observed. Despite this, students showed the lowest level (Idiosyncratic) for the Analysing and Interpreting Data construct. This was a predicted outcome since the assessment requiring the students to make interpretations, comparisons, statistical inferences, reasoning, and thinking are given little attention in the Malaysian KBSM statistical teaching and learning process despite being included in the Mathematics KBSM syllabus. Secondly, these aspects are not usually prompted in examination questions, causing students to have less exposure to them, which possibly led the students to exhibit the lowest level of reasoning in the Analysing and Interpreting Data construct. The findings of the study did not support the study of Ismail et al. (2015), which used similar constructs to assess students' statistical reasoning among Chinese primary school students in Johor, Malaysia. Most of the students in their study could achieve the highest level (Analytical) in all the constructs of statistical reasoning. Some factors might contribute to these differences of findings such as the location of the study, curriculum, and cultural differences (Liu \& Garfield, 1998; Tempelaar, 2004; Wang et al., 2009).

In the assessment on attitudes towards statistics, this study found the students held positive attitudes towards statistics, indicating they felt positive when learning about statistical topics in mathematics. 
This finding supports the findings by Saidi and Siew (2019a), which also ascertained that tenth-grade science stream students from a district in Sabah, Malaysia held positive attitudes towards statistics. Similar findings were also observed in studies conducted by Carmona et al. (2005), Mahmud (2010), Ashaari et al. (2012), Zhang et al. (2012), and Naccache (2012), which revealed students' positive attitudes towards statistics in higher institutions of learning. Moreover, in terms of students' attitudes towards statistics components, this study discovered the students held positive attitudes for all the components of attitudes towards statistics. Students showed more positive attitudes in Effort, followed by Cognitive Competence, Interest, Affect, Difficulty and Value. Similar patterns of findings were noted in Saidi and Siew's (2019a) study, where Tenth Grade science stream students in a district in Sabah, Malaysia held a positive attitude in all of the components of attitudes towards statistics except for the Value component which was neutral. The findings of this study also support Hommik and Liuk (2017), which stated that Estonian upper secondary school students held a positive attitude in all the components of attitudes towards statistics. Conversely, studies show that in higher institutions, students exhibited lower level of attitudes in at least one of the attitudes towards statistics components especially in the Difficulty component (Carmona et al., 2005; Coetzee \& Van der Merwe, 2010; Zhang et al., 2012). This contrast in findings could have resulted due to the disparity in the difficulty of learning statistics between differing levels of education. Students of more advanced levels of education are exposed to more challenging, difficult, and complicated statistical concepts and formulas compared to high school students. This could be the cause of negative attitudes towards statistics among students in the higher institution. This would align with Chiesi and Primi's (2010a) finding that many students in the tertiary level perceived statistics as one of the most difficult subjects or courses.

A moderate level of statistical anxiety found in this study indicates that overall, the students were moderately anxious when learning statistical topics in mathematics. This finding supports the findings by Rosli et al. (2017) and Maat et al. (2017), which suggested that university students also held a moderate level of statistical anxiety. Students held a moderate anxiety level in the Examination Anxiety and Interpretation Anxiety components, but showed low anxiety in the Asking for Help Anxiety component. The findings of the study did not corroborate the findings of the study conducted by Onwuegbuzie (1999) and William (2010), which discovered that university students showed high anxiety in at least one of the statistics anxiety components, especially in the Interpretation Anxiety and Test and Class Anxiety components. Comparatively, it was observed that the students in this study were less anxious than students in higher institutions when it came to interpretation and examination in statistics. Two factors that might contribute to this are differences in the respective statistical curriculum and focus of teaching. At the higher level of education, statistics is usually presented as a compulsory or pre-requisite course during undergraduate or post-graduate studies. Thus, given the compulsory and high-stakes nature of statistics courses, it is not surprising that higher institutions' students regard statistics courses as the most distressing and anxiety inducing course in their undergraduate programs (Baloglu, 2004; Chew \& Dillon, 2014; Hanna et al., 2008). Compared with statistical teaching at universities, the statistical teaching in secondary school only exposes a small, selected portion of statistics, and these statistical topics have already been integrated into the mathematics curriculum. Thus, statistics in secondary schools might be viewed as less intimidating as compared to statistics taught in higher institutions.

\subsection{RELATIONSHIP BETWEEN ATTITUDE AND ANXIETY IN STATISTICS WITH OVERALL STATISTICAL REASONING}

The relationship between attitudes towards statistics and overall statistical reasoning in this study was discovered to be positive, but demonstrated a very weak relationship. This indicates the ability of students' statistical reasoning was very weakly related to their positive attitude towards statistics, where higher statistical reasoning is associated with more positive attitudes and vice versa. Additionally, the study also discovered a very weak positive linear relationship between the Cognitive Competence and Value components with overall statistical reasoning, suggesting that students' statistical reasoning ability was very weakly related with an accelerated interest towards the knowledge and skills used in statistics and how they value it in their daily life. With a positive attitude towards statistical knowledge, skills, relevance, and usefulness, students may perform more desirably in the statistical reasoning assessment, while a negative attitude may result in unsatisfactory outcomes. Similar findings were also 
observed in the study by Estrada et al. (2005) that highlighted the teachers' attitudes towards statistics had a positive and very weak relationship with statistical reasoning. This study further supported the findings by Tempelaar (2004), Estrada et al. (2005), and Chiesi and Primi (2010a), which found positive and very weak relationships between Cognitive Competence and statistical reasoning. The finding of the very weak positive relationship between Value and statistical reasoning further confirmed the findings by Estrada et al. (2005).

Regarding the assessment on the relationship between statistics anxiety and overall statistical reasoning, this study showcased a negative and very weak relationship between students' statistics anxiety and overall statistical reasoning. This finding substantiates the findings by Primi et al. (2018) in which a very weak negative relationship between students' statistics anxiety and statistical reasoning was found for psychology students. A very weak negative linear relationship between the Asking for Help Anxiety and Interpretation Anxiety components with overall statistical reasoning was among the findings in this study. This proposes that the ability of students in statistical reasoning was weakly related to the feeling of anxiousness or being worried when asking the mathematics teacher or other students about statistical topics, and when having to study and understand anything related to statistics, be it the information, formulae, equations, and concepts. Students who feel uneasy or anxious to ask questions for fear of embarrassment or judgement may have gaps in their understanding and knowledge which results in lower performance in statistics (Ali \& Iqbal, 2012).

\subsection{IMPORTANT PREDICTORS OF STATISTICAL REASONING}

Based on the results from the multiple linear regression analysis, the Value, Interest, and Interpretation Anxiety components were found to be important predictors for overall statistical reasoning. Therefore, it is perceived that the students' attitudes towards the usefulness, relevance, and worth of statistics for individuals and their daily and professional life was positively related to their statistical reasoning. In other words, higher appreciation and value of statistics is associated with better performances in statistical reasoning. This finding further supported Tempelaar (2004), which reported people with positive attitudes towards statistics had better outcomes in statistical reasoning performance via the Value component.

In a multivariable context, the Interest component was found to have a negative relationship with the overall statistical reasoning, which may imply that students who show a high interest in statistics do not necessarily have high ability in statistical reasoning. Interest as discussed by Harackiewicz et al. (2016) is a powerful motivational process that can boost learning and guide careers and is crucial to academic success. In this study, however, the opposite situation was observed, but it can be justified by Slootmaeckers (2014): students with less interest in statistics might study harder in order to ensure that they do not fail for the examination, which in turn would give a better statistical achievement.

In addition, the presence of Interest as an important predictor of overall statistical reasoning in the regression model might be due to the inclusion of Value and the collinear relationship between the two components. Based on the Expectancy-Value framework on which the SATS instrument was built, Interest and Value belong to the same Task-Value component, with Interest representing intrinsic value and Value representing extrinsic value (see Ramirez et al. 2012). The collinearity of these two valuecomponents leads us to more nuanced conclusions: accounting for the effect of Value, the effect of Interest is negative. In otherwords, Interest serves as a negative predictor only amongst students with similar levels of Value. After all, Value drives extrinsic motivation tolearn, while Interest triggersintrinsic motivation to learn. Many studies have found extrinsic motivation was the betterpredictor (Makki \& Abid, 2017; Pirzada et al., 2019; Miao et al., 2020) and that intrinsic motivation may lead students tocreate their own curriculum since they learn based on what they are interested in, not what the teachers ask them to learn, especially if the curriculum is strongly teacher-centered.

Another finding from this study suggests that the students' anxiety was negatively related to their statistical reasoning when they attempted to interpret statistical data and understand the formulas used in statistics. This suggests they performed poorly in statistical reasoning if they felt too anxious or tense when interpreting or trying to understand statistical topics, formula, or concepts. This is a real concern since anxiety impedes students' learning, especially when they have to do revisions. Interpretation Anxiety makes it difficult for students to study and revise statistical lessons, which in turn negatively affects their performance in statistical reasoning. This finding is consistent with Agus et al. (2015), 
which found that the Interpretation Anxiety component fostered a negative relationship on the students' reasoning ability, especially on the Italian sample who worked without time pressure.

\section{CONCLUSION AND RECOMMENDATION}

This study fills a gap in the literature by assessing secondary school students' statistical reasoning, attitudes towards statistics, and statistics anxiety. Based on the findings of the study, it was revealed that the students' statistical reasoning overall was in the Quantitative level, as well as in the constructs of Describing Data, Organising Data, and Representing Data. Despite the high level of statistical reasoning achieved by the students on these three constructs, there was a low-level achievement in statistical reasoning. This was particularly true for the Analysing and Interpreting Data construct, which required students to give their inferences, reasons, or justifications for their choice of answers. As a suggestion for instruction, mathematics teachers should give extra attention to developing students' statistical reasoning for the Analysing and Interpreting the Data construct, since in fact, this construct is the core of statistical reasoning. It was noted that the students in the study could master the computational and procedural aspects in statistical reasoning.

These findings should be treated with caution due to the number of items used to measure the construct of statistical reasoning. For instance, the items in Organising Data represented half of the total statistical reasoning score in SRTS instrument, which might indicate that students' overall statistical reasoning revloves around this particular construct. Describing Data and Analysing and Interpreting Data contained only two items in SRTS, which might be insufficient to measure these particular constructs. Thus, additional studies should be done to improve the SRTS instrument, for instance, creating more items for constructs that currently have fewer items.

Nonetheless, the Mathematics KSSM curriculum introduced in 2017 has changes in the statistics topics. Some elements of statistical reasoning have been included in the new Mathematics textbook. For instance, as early as in Seventh Grade, students will be learning about Data Handling, which comprises one of the constructs of statistical reasoning assessed in this study. Therefore, it would be beneficial for future studies to be conducted on the students who have been following the KSSM curriculum to see whether this current curriculum could improve students' performances in statistical reasoning.

This study also revealed an association between several attitude and anxiety components anxiety and statistical reasoning. Since the magnitude of the relationships were very weak, however, we recommended that statistics researchers continue to explore the relationship between the three main scales of the study, at least with respect to secondary students. As we await future results, several actions may be undertaken by the mathematics teacher to improve students' attitude in this aspect, such as enabling students to attempt statistical practices during the classes (Chiesi \& Primi, 2010a) as well as use real life applications in statistics classes (Naccache, 2012). These actions should contribute to students' awareness of the subject's utility, which in turn encourages them to appreciate why statistics is worth learning and is a useful tool for their professional training.

According to Araki (1995), if attitudes indeed prove to be an important factor in students' achievement, teachers can adjust their instruction to include more motivating elements, especially for low-achieving students. Cherney and Cooney (2005) asserted that the learning process and achievement for statistics in a class of highly anxious students can be optimised by adjusting the instructors' pedagogical styles. The styles may include use of humor in teaching (Schact \& Stewart, 1990) and displaying immediacy behaviors (Williams, 2010). Students' anxiety in statistics should also be addressed at the beginning of the lesson so that the appropriate curriculum adjustments can be provided for the anxious students. As for students' learning strategies, students who used rehearsal, elaboration, organisation, critical thinking, and effort regulation strategies experienced lower levels of statistics anxiety (Baloglu et al., 2011). It is suggested that students who face these predicaments may need to learn to overcome their insecurities in order for better results in the statistical reasoning assessment to be realised. 


\section{ACKNOWLEDGEMENTS}

We would like to express our sincere gratitude to Universiti Malaysia Sabah, Sabah, Malaysia for supporting this research under Grant No. FRG0462-2017.

\section{REFERENCES}

Agus, M., Hitchcott, P. K., Penna, M. P., Peró-Cebollero, M. \& Guàrdia-Olmos, J. (2016). Probabilistic reasoning under time pressure: An assessment in Italian, Spanish and English psychology undergraduates. Journal of Physics: Conference Series, 772. https://iopscience.iop.org/article/10.1088/1742-6596/772/1/012042/pdf

Agus, M., Peró-Cebollero, M., Penna, M. P., \& Guàrdia-Olmos, J. (2015). Comparing psychology undergraduates performance in probabilistic reasoning under verbal-numerical and graphicalpictorial problem presentation format: What is the role of individual and contextual dimensions? Eurasia Journal of Mathematics, Science \& Technology Education, 11(4), 735-750. https://doi.org/10.12973/eurasia.2015.1382a

Ali, A. Z., \& Iqbal, F. (2012). Statistics anxiety among psychology graduates: An analysis. International Proceedings of Economics Development \& Research, 53(25), 113-117. http://www.ipedr.com/vol53/025-BCPS2012-C10026.pdf

Araki, L. (1995). An exploratory study of student attitudes toward statistics and their retention of statistical concepts [Master thesis, California State University].

Ashaari, N., Mohamad Judi, H., Mohamed, H., \& Tengku Wook, T. M. (2012). Student's attitude towards statistics course. Procedia Social Behavioral Sciences, 18, 287-294. https://doi.org/10.1016/j.sbspro.2011.05.041

Baloglu, M. (2004). Statistics anxiety and mathematics anxiety: Some interesting differences. Educational Research Quarterly, 27(3), 38-48. https://files.eric.ed.gov/fulltext/EJ792861.pdf

Baloglu, M., Deniz, M. E., \& Kesici, Ş. (2011). A descriptive study of individual and cross-cultural differences in statistics anxiety. Learning and Individual Differences, 21(4), 387-391. https://doi.org/10.1016/j.lindif.2011.03.003

Bell, J. A. (2001). Length of course and levels of statistics anxiety. Education, 121(4), 713-716.

Ben-Zvi, D., \& Garfield, J. B. (2004). The challenge of developing statistical literacy, reasoning and thinking. Kluwer Academic. https://doi.org/10.1007/1-4020-2278-6

Bond, T. G., \& Fox, C. M. (2015). Applying the Rasch model: Fundamental measurement in the human science (3rd ed.). Lawrence Erlbaum.

Boone, W. J., Staver, J. R., \& Yale, M. S. (2014). Rasch analysis in the human sciences. Springer.

Carmona, J., Martinez, R. J., \& Sanchez, M. (2005). Mathematical background and attitudes toward statistics in a sample of Spanish college students. Psychological Reports, 97(1), 53-62. https://doi.org/10.2466/pr0.97.1.53-62

Chan, S. W., \& Ismail, Z. (2013). Assessing misconceptions in reasoning about variability among high school students. Procedia - Social and Behavioral Sciences, 93 (2013), 1478-1483. https://doi.org/10.1016/j.sbspro.2013.10.067

Chan, S. W., Ismail, Z. \& Sumintono, B. (2015a). The impact of statistical reasoning learning environment: A Rasch analysis. Advanced Science Letters, 21(5), 1211-1215. https://doi.org/10.1166/asl.2015.6077

Chan, S. W., Ismail, Z., \& Sumintono, B. (2015b). A refined technology-based statistical reasoning assessment tool in descriptive statistics. Advanced Science Letters. 21(7), 2352-2355. https://doi.org/10.1166/asl.2015.6273

Cherney, I. D., \& Cooney, R. R. (2005). Predicting student performance in a statistics course using the mathematics and statistics perception scale (MPSP). Transactions of the Nebraska Academy of Sciences and Affiliated Societies, 30, 1-8.

Chew, P. K. H., \& Dillon, D. B. (2014). Statistics anxiety update: Refining the construct and recommendations for a new research agenda. Perspectives on Psychological Science, 9(2), 196208. https://doi.org/10.1177/1745691613518077 
Chew, P. K. H., \& Dillon, D. B. (2015). Statistics anxiety and attitudes toward statistics. In D. Chhabra (Ed.), Proceedings of the 4th Annual International Conference on Cognitive and Behavioral Psychology (CBP 2015), February 9-10, Singapore (pp. 1-15).

Chiesi, F., \& Primi, C. (2010a). Cognitive and non-cognitive factors related to students' statistics achievement. Statistics Education Research Journal, 9(1), 6-26. https://doi.org/10.52041/serj.v9i1.385

Chiesi, F., \& Primi, C. (2010b). Learning probability and statistics: Cognitive and non-cognitive factors related to psychology students' achievement. In C. Reading, (Ed.), Data and context in statistics education: Towards an evidence-based society. Proceedings of the Eighth International Conference on Teaching Statistics (ICOTS8), July 11-16, Ljubljana, Slovenia. International Statistical Institute. https://iase-web.org/documents/papers/icots8/ICOTS8_7C1_CHIESI.pdf

Chua, Y. P. (2009). Statistik penyelidikan lanjutan [Advanced research statistics]. McGraw Hill.

Coetzee, S., \& Van der Merwe, P. (2010). Industrial psychology students' attitudes towards statistics. SA Journal of Industrial Psychology, 36(1), 1-8. https://doi.org/10.4102/sajip.v36i1.843

Estrada, A., Batanero, C., Fortuny, J. M., \& Díaz, C. (2005). A structural study of future teachers' attitudes towards statistics. In K. Krainer \& N. Vondrová (Eds.), Proceedings of the Ninth Congress of the European Society for Research in Mathematics Education (CERME9), February 4-8, Prague, Czech Republic (pp. 508-517).

Foo, K., Idris, N., Mohamed, I., \& Foo, L. (2016). A multiple regression model of statistical reasoning: A Malaysian context. OIDA International Journal of Sustainable Development, 9(10), 59-70. https://ssrn.com/abstract=2896527

Garfield, J. B. (1998). The statistical reasoning assessment. Development and validation of a research tool. In L. Pereira-Mendoza, L. Seu Kea, T. Wee Kee, \& W. K. Wong (Eds.), Proceedings of the Fifth International Conference on Teaching of Statistics (ICOTS5), Singapore (Vol. 2, pp. 781786). IASE. https://iase-web.org/documents/papers/icots5/Topic6u.pdf?1402524957

Garfield, J. B., \& Chance, B. (2000). Assessment in statistics education: Issues and challenges. Mathematics Thinking and Learning, 2(1\&2), 99-125. https://doi.org/10.1207/S15327833MTL0202_5

Hair, J. F., Black, W. C., Babin, B. J., \& Anderson, R. E. (2014). Multivariate data analysis (7th ed.). Pearson Education Limited.

Hanna, D., Shevlin, M., \& Dempster, M. (2008). The structure of the Statistics Anxiety Rating Scale: A confirmatory factor analysis using UK psychology students. Personality and Individual References, 45, 68-74. https://doi.org/10.1016/j.paid.2008.02.021

Hanna, D., \& Dempster, M. (2009). The effect of statistics anxiety on students' predicted and actual test scores. The Irish Journal of Psychology, 30(3-4), 201-209. https://doi.org/10.1080/03033910.2009.10446310

Harackiewicz, J. M., Smith, J. L., \& Prinisk, S. J. (2018). Interest matters: The importance of promoting interest in education. Policy Insights Behavioral \& Brain Science, 3(2), 220-227. https://doi.org/10.1177/2372732216655542

Hommik, C., \& Luik, P. (2017). Adapting the Survey of Attitudes Toward Statistics (SATS-36) for Estonian secondary. Statistics Education Research Journal, 16(1), 228-39. https://doi.org/10.52041/serj.v16i1.229

Horikawa, M., \& Yagi, A. (2012). The relationships among trait anxiety, state anxiety and the goal performance of penalty shoot-out by university soccer players. PLoS ONE, 7(4), e35727. https://doi.org/10.1371/journal.pone.0035727

Ismail, Z., \& Chan, S. W. (2015). Malaysian students' misconceptions about measures of central tendency: An error analysis. In M. Sham Mohamad, W. Nur Syahidah Wan Yusoff, N. Aida Zuraimi Md Noar, R. Zakaria \& M. Rashid Ab Hamid (Eds.), Empowering the applications of statistical and mathematical sciences. Proceedings of the 2nd ISM International Statistical Conference 2014 (ISM-II), AIP Conference Proceedings 1643, August 12-14, 2014, Pahang, Malaysia (pp. 93-100). https://doi.org/10.1063/1.4907430

Ismail, Z. Lee, V. L. \& Chan, S. W. (2015). Assessing statistical reasoning among Chinese primary school students. Advanced Science Letters, 21(7), 2239-2242. https://doi.org/10.1166/as1.2015.6254 
Jacob, B., \& Doerr, H. M. (2013). Students' informal inferential reasoning when working with the sampling distribution. In M. A. Mariotti et al. (Eds.), Eighth Congress of European Research in Mathematics Education (CERME8), February 6-10, Antalya, Turkey (pp. 829-839).

http://cerme8.metu.edu.tr/wgpapers/WG5/WG5_Jacob.pdf

Jones, G. A., Langrall, C. W., Mooney, E. S., \& Thornton, C. A. (2004). Models of development in statistical reasoning. In D. Ben-Zvi \& J. Garfield (Eds). The challenge of developing statistical literacy, reasoning, and thinking (pp. 97-117). Kluwer Academic. https://doi.org/10.1007/14020-2278-6_5

Jones, G. A., Thornton, C. A., Langrall, C. W., Mooney, E. S., Perry, B., \& Putt, I. A. (2000). A framework for characterizing children's statistical thinking. Mathematical Thinking and Learning, 2, 269-307. https://doi.org/10.1207/S15327833MTL0204_3

Lay, Y. F., Khoo, C. H., \& Ley, C. M. (2016). Pengenalan kepada analisis data dengan IBM SPSS Statistics 19 dalam penyelidikan sains sosial. [Introduction to data analysis with IBM SPSS 19 in social science research]. Penerbit Universiti Malaysia Sabah.

Lester, D. (2016). Predicting success in psychological statistics courses. Psychological Reports, 118(3), 772-777. https://doi.org/10.1177/0033294116647687

Liau, A. K., Kiat, J. E., \& Nie, Y. (2015). Investigating the pedagogical approaches related to changes in attitudes toward statistics in a quantitative methods course for psychology undergraduate students. The Asia-Pacific Education Researcher, 24(2), 319-27. http://dx.doi.org/10.1007/s40299014-0182-5

Maat, S. M., Zakaria, E., \& Rosli, R. (2016). Descriptive study on students' anxiety towards statistics. Indian Journal of Science and Technology, 9(48), 1-6. https://doi.org/10.17485/ijst/2016/v9i48/90779

Mahmud, Z. (2010). A discriminant analysis of perceived attitudes toward statistics and profile identification of statistics learners. In M. Demiralp, N. A. Baykara \& N. E. Mastorakis (Eds.), Proceedings of the 2nd WSEAS International Conference on Multivariate Analysis and its Application in Science and Engineering (MAASE '09), May 30-June 1, Istanbul, Turkey (pp. 4147). https://pdfs.semanticscholar.org/4680/fba8f16ecadb7392f073a94b402ca8df4128.pdf

Mahmud, Z., \& Osman, N. H. (2010). Statistical competency and attitude towards learning elementary statistics: A case of SMK Bandar Baru Sg Buloh. Proceedings of the Regional Conference on Statistical Sciences (RCSS'10), June 14-18, Kota Bharu, Malaysia.

Makki, A., \& Abid, M. (2017). Influence of intrinsic and extrinsic motivation on employee's task performance. Studies in Social Science, 4(1), 38-4.

Martins, J., Nascimento, M., \& Estrada, A. (2011). Attitudes of teachers towards statistics: A preliminary study with Portuguese teachers. In M. Pytlak, T. Rowland \& E. Swoboda (Eds.), Proceedings of Seventh Congress of the European Society for Research in Mathematics Education (CERME 7), February 9-13, Rzeszow, Poland (pp. 1-10).

Miao, S., Rhee, J., \& Jun, I. (2020). How much does extrinsic motivation or intrinsic motivation affect job engagement or turn over intention? A comparison study in China. Sustainability, 1-18. http://dx.doi.org/10.3390/su12093630

Mohamad Judi, H., Mohamed, H., \& Tengku Wook, T. M. (2011). Students profile based on attitude towards statistics. Procedia Social and Behavioral Sciences, 18, 266-72. https://doi.org/10.1016/j.sbspro.2011.05.038

Mooney, E. S. (2002). A framework for characterizing middle school students' statistical thinking. Mathematical Thinking and Learning, 4(1), 23-63. https://doi.org/10.1207/S15327833MTL0401_2

Naccache, H. S. (2012). Factors related to student performance in statistics courses in Lebanon [Doctoral dissertation, The University of Southern Mississippi].

Nasser, F. M. (2004). Structural model of the effects of cognitive and affective factors on the achievement of Arabic-speaking pre-service teachers in introductory statistics. Journal of Statistics Education, 12 (1), 1-19. https://doi.org/10.1080/10691898.2004.11910717

Olani A, Hoekstra R, Harskamp E., \& van der Werf G. (2011). Statistical reasoning ability, selfefficacy, and value beliefs in a reform-based university statistics course. Electronic Journal of Research in Educational Psychology, 9(23), 49-72. http://dx.doi.org/10.25115/ejrep.v9i23.14

Onwuegbuzie, A. J., DaRos, D., \& Ryan, J. M. (1997). The components of statistics anxiety: a phenomenological study. Focus on Learning Problems in Mathematics, 19(4), 11-35. 
Onwuegbuzie, A. J., \& Daly, C. E. (1999). Perfectionism and statistics anxiety. Personal and Individual Differences, 26(6), 1089-1102. https://doi.org/10.1016/S0191-8869(98)00214-1

Onwuegbuzie, A. J. (2003). Modeling statistics achievement among graduate students. Educational and Psychological Measurement, 63(6), 1020-1038. https://doi.org/10.1177/0013164402250989

Pirzada, Z., Bukhari, N., Mahar, S., Phulpoto, N., \& Mirani, S. (2019). Intrinsic and extrinsic motivators: Predictors of employees performance - A case study of IBA, SUKKUR. Quest Research Journal, 17(2), 71-77.

Primi, C., Donati, M. A., \& Chiesi, F. (2018). The role of statistics anxiety in learning probability. In C. Batanero \& E. J. Chernoff (Eds.) Teaching and Learning Stochastics: Advances in Probability Education Research (pp. 145-160). Springer. https://doi.org/10.1007/978-3-319-72871-1_9

Ramirez, C., Schau, C., \& Emmioğlu, E. (2012). The importance of attitudes in statistics education. Statistics Education Research Journal, 11(2), 57-71. https://doi.org/10.52041/serj.v11i2.329

Rosli, M. K., \& Maat, S. M. (2017). Attitude towards statistics and performance among post-graduate students. Proceedings of the International Conference on Education, Mathematics and Science 2016 (ICEMS2016) in Conjunction with 4th International Postgraduate Conference on Science and Mathematics, November 19, Perak, Malaysia. https://doi.org/10.1063/1.4983881

Rosli, M. K., Maat, S. M., \& Rosli, R. (2017). Students' attitude and anxiety towards statistics: A descriptive analysis. Research on Education and Psychology (REP), 1(1), 47-56. https://dergipark.org.tr/en/download/article-file/555519

Saidi, S. S., \& Siew, N. M. (2019a). Assessing students' understanding of the measures of central tendency and attitude towards statistics in rural secondary schools. International Electronic Journal of Mathematics Education,14(1), 73-86. https://doi.org/10.12973/iejme/3968

Saidi, S. S., \& Siew, N. M. (2019b). Reliability and validity analysis of statistical reasoning test survey instrument using the Rasch measurement model. International Electronic Journal of Mathematics Education, 14(3), 535-546. https://doi.org/10.29333/iejme/5755

Saidi, S. S., \& Siew, N. M. (2019c). Investigating the validity and reliability of Survey Attitude Towards Statistics instrument among rural secondary school students. International Journal of Educational Methodology, 5(4), 651-661. https://doi.org/10.12973/ijem.5.4.651

Salim, N. R., \& Mohd Ayub, A. F. (2017). Relationship between mathematics statistics engagement and attitudes towards statistics among undergraduate students in Malaysia. In A. Kilicman, H. Mohan Srivastava, M. Mursaleen \& C. Masood Khalique (Eds), 2nd International Conference and Workshop on Mathematical Analysis 2016, AIP Conference Proceedings 1795, August 2-4, Langkawi, Malaysia. https://doi.org/10.1063/1.4972170

Schact, S. P., \& Stewart, B. J. (1990). What's funny about statistics? A technique for reducing student anxiety. Teaching Sociology, 18(1), 52-56. https://www.jstor.org/stable/1318231

Schau, C., Stevens, J., Dauphinee, T. L., \& Del Vecchio, A. (1995). The development and validation of the Survey of Attitudes Towards Statistics. Educational and Psychological Measurement, 55(5), 868-875. https://doi.org/10.1177/0013164495055005022

Schau, C. (2003). Students' attitudes: The "other" important outcome in statistics education. Paper presented at the 2003 Joint Statistical Meetings: Section on Statistical Education, San Francisco, CA. http://statlit.org/pdf/2003SchauASA.pdf

Shaughnessy, J. M., Garfield, J., \& Greer, B. (1996). Data handling. In A. J. Bishop, K. Clements, C. Keitel, J. Kilpatrick \& C. Laborde (Eds.), International handbook of mathematics education (Pt. 1, pp. 205-237). Kluwer Academic. https://doi.org/10.1007/978-94-009-1465-0_7

Slootmaeckers, K. (2014). Too afraid to learn: Attitudes towards statistics as a barrier to learning statistics and to acquiring quantitative skills. Politics, 34(2), 191-200. https://doi.org/10.1111/14679256.12042

Spielberger, C. D. (1966). Anxiety and behavior. Academic Press.

Tanaka, A., Takehara, T., \& Yamauchi, H. (2006). Achievement goals in a presentation task: Performance expectancy, achievement goals, state anxiety, and task performance. Learning and Individual Differences, 16(2), 93-99. https://doi.org/10.1016/j.lindif.2005.06.005

Tempelaar, D. (2004). Statistical reasoning assessment: An analysis of the SRA instrument. Proceedings of ARTIST Roundtable Conference on Assessment in Statistics, August 1-4, Appleton, WI. http://www.rossmanchance.com/artist/proceedings/tempelaar.pdf 
Tempelaar, D. T., van Der Loeff, S. S., \& Gijselaers, W. H. (2007). A structural equation model analyzing the relationship of students' attitudes toward statistics, prior reasoning abilities and course performance. Statistics Education Research Journal, 6(2), 78-102. https://iaseweb.org/documents/SERJ/SERJ6(2)_Tempelaar.pdf

Tremblay, P. F., Gardner, R. C., \& Heipel, G. (2000). A model of the relationships among measures of affect, aptitude, and performance in introductory statistics. Canadian Journal of Behavioral Science, 32(1), 40-48. https://doi.org/10.1037/h0087099

Turegun, M., \& Reeder, S. (2011). Community college students' conceptual understanding of statistical measures of spread. Community College Journal of Research and Practice, 35(5), 410-426. https://doi.org/10.1080/10668920903381854

Ulusoy, A., \& Altay, K. (2017). Analyzing the statistical reasoning levels of pre-service elementary school teachers in the context of a model eliciting activity. International Journal of Research in Education and Science (IJRES), 3(1), 20-30.

Vigil-Colet, A., Lorenzo-Seva, U., \& Condon, L. (2008). Development and validation of the statistical anxiety scale. Psicothema, 20(1), 174-180. http://www.psicothema.com/PDF/3444.pdf

Wang, W., Wang, X., \& Chen, G. (2009). Survey and analysis of the statistical reasoning among high school students in China and Dutch. Journal of Mathematics Education, 2(1), 15-26. http://educationforatoz.com/images/_2_Wenfang_Wang_Final.pdf

Williams, A. S. (2010). Statistics anxiety and instructor immediacy. Journal of Statistics Education, 18(2), 1-18. http://jse.amstat.org/v18n2/williams.pdf

Wilson, T., \& MacGillivray, H. (2006). Numeracy and statistical reasoning on entering university. In Rossman \& Chance (Eds.). Working cooperatively in statistics education. Proceedings of the Seventh International Conference on Teaching Statistics (ICOTS-7), July 2-7, Salvador, Brazil. https://www.stat.auckland.ac.nz/ iase/publications/17/C136.pdf

Wilson, T. M. (2006). Statistical reasoning at the secondary tertiary interface. [Doctoral dissertation, Queensland University of Technology]. https://eprints.qut.edu.au/16358/3/Therese\%20Wilson\%20Thesis.pdf

Zaidan, A., Ismail, Z., Mohamad Yusof, Y., \& Kashefi. H. (2012). Misconceptions in descriptive statistics among postgraduates in social sciences. Procedia-Social and Behavioral Sciences, 46(2012), 3535-3540. https://doi.org/10.1016/j.sbspro.2012.06.100

Zhang, Y., Shang, L., Wang, R., Zhao, Q., Li, C., Xu, Y., \& Su, H. (2012). Attitudes toward statistics in medical postgraduates: Measuring, evaluating and monitoring. BMC Medical Education, 12(117), 1-8. https://doi.org/10.1186/1472-6920-12-117

SITI SHAHIRAH SAIDI

Faculty of Psychology and Education Universiti Malaysia Sabah 